\title{
Uso de Cultivos Lácticos Para Prolongación de Vida Útil de Frutas de Mayor Consumo En Lima - Perú
}

\section{Ruth Liliana Cristóbal Delgado (I), Dora Jesús Maurtua Torres (I)}

(I) UPCH - Universidad Peruana Cayetano Heredia (Av. Honorio Delgado 430. Urb. Ingeniería. San Martín de Porres. Lima - Perú)

\section{Resumo}

El consumo de frutas se ha incrementado en los últimos años debido a un interés en el área de nutrición y salud. Por ende, la demanda implica una mejor calidad tanto organoléptica como microbiológica de estos productos. Para salvaguardar la calidad e inocuidad, se trabajan en alternativas naturales como la bioconservación. En esta área se viene desarrollando el uso de cultivos lácticos debido a las sustancias antimicrobianas que sintetizan. Este trabajo propone el uso de cultivos lácticos para prolongar la vida útil en anaquel de frutas de mayor consumo en nuestra localidad. Se emplearon uvas Red Globe y mangos Edward preparándose dos grupos, uno control y otro impregnado con cultivos lácticos. Ambos grupos fueron evaluados periódicamente para determinar si el tratamiento con cultivos lácticos permitía una disminución en tiempo del deterioro de estas frutas. Se realizaron lavados de las muestras con solución salina y diluciones decimales seriadas con siembras en agar de recuento en placa, agar MacConkey, agar Sangre, agar MRS y agar Sabouraud. Luego, se realizó el recuento y la identificación de los organismos aislados. Las uvas presentaron señales de deterioro como ablandamiento de su superficie a partir del día 8 en el grupo control, mientras que en el grupo tratamiento el deterioro se presentó a partir del día 15. Para el caso de los mangos, el grupo control presentó manchas y ablandamiento a partir del día 10 y el grupo tratamiento a partir del día 15. Los recuentos de aerobios mesófilos para el grupo tratamiento disminuyó de 1600000 ufc/100 g a 17000 ufc/100 $\mathrm{g}$ para el caso de uvas y para mangos de $3000 \mathrm{ufc} / 250 \mathrm{~g}$ a $212 \mathrm{ufc} / 250 \mathrm{~g}$. 
No hubo presencia de Salmonella. Se reportó presencia de coliformes y S. aureus. La presencia de levaduras se ve disminuida tanto para uvas y mangos en el grupo tratamiento a diferencia del grupo control. De acuerdo a los resultados obtenidos, se demuestra que los cultivos lácticos empleados en el estudio permitieron extender la vida útil de uvas y mangos, de esta manera se controla el deterioro del producto para beneficio de productores y consumidores.

Palavras-Chave: cultivos lácticos, mangos, uvas, bioconservación Agência de Fomento: 